\title{
Desempenho e características qualitativas da carcaça e da carne de cordeiros terminados em confinamento alimentados com dietas contendo soja grão ou gordura protegida
}

\author{
Alexandre Rodrigo Mendes Fernandes ${ }^{1}$, Marco Antonio Previdelli Orrico Junior ${ }^{2}$, Ana \\ Carolina Amorim Orrico $^{1}$, Fernando Miranda de Vargas Junior $^{1}$, Arley Borges de \\ Moraes Oliveira ${ }^{3}$
}

\footnotetext{
1 Universidade Federal da Grande Dourados /Faculdade de Ciências Agrárias.

2 Programa de Pós-Graduação em Zootecnia - FCAV/Unesp.

3 Programa de Pós-Graduação em Zootecnia - FCA/UFGD.
}

RESUMO - O objetivo foi avaliar o desempenho, as características das carcaças e a qualidade da carne de cordeiros Santa Inês, terminados em confinamento, alimentados com dietas contendo $60 \%$ de concentrado e enriquecidas com soja grão ou gordura protegida. Os concentrados foram compostos de farelo de soja, milho, farelo de trigo, ureia, núcleo mineral, soja grão ou gordura protegida. Como volumoso foi utilizado o feno de capim-tifton 85. Foram utilizados 24 cordeiros com aproximadamente 19,30 $\pm 1,77 \mathrm{~kg}$ e média de idade de 5 meses alojados em baias individuais por um período de 105 dias (21 de adaptação e 84 dias de período experimental). Os animais foram pesados ao início do experimento e a intervalos de 28 dias, com a finalidade de acompanhar o ganho de peso dos animais. Findo o experimento, foram abatidos para mensurações nas carcaças e avaliação das características quantitativas. Após o resfriamento das carcaças por 24 horas, foram retiradas amostras do lombo para análises da qualidade da carne. O delineamento experimental foi o inteiramente casualizado, com três tratamentos e oito repetições. Os animais que receberam a gordura protegida apresentaram maior ganho em peso (0,24 kg/dia). As dietas contendo soja grão ou gordura protegida proporcionaram melhor conversão alimentar (4,80 e 4,06 respectivamente). O enriquecimento da dieta com soja grão ou gordura protegida não promove diferenças significativas nas características de carcaça nem na qualidade da carne.

Palavras-chave: área de olho-de-lombo, características de carcaça, ganho de peso diário, maciez, ovinos, textura

\section{Performance and qualitative characteristics of carcasses and meat of lambs finished in confinement and fed diets containing soybean grain or protected fat}

\begin{abstract}
The objective of this work was to evaluate performance, carcass traits and meat quality of Santa Inês lambs, finished in feedlot, fed diets containing $60 \%$ concentrate and enriched with soybean grain or with protected fat. The concentrates were composed with soybean meal, corn, wheat meal, urea, mineral mixture, soybean grain or protected fat. Tifton-85 hay was used as roughage. It was used 24 lambs with approximately $19.30 \pm 1.77 \mathrm{~kg}$ and at average age of five months. The animals were housed in individual pens for a period of 105 days (21 days of adaptation and 84 days of experimental period). The animals were weighed at the beginning of the experimental period and at every 28-day interval aiming at following weight gains in the animals. When the experiment finished, the animals were slaughtered for measurements on carcasses and assassement of quantitative characteristics. After cooling carcasses for 24 hours, samples were taken from the loin for meat quality analysis. The experimental design was a completely randomized design with three treatments and eight replicates. Animals fed protected fed presented better feed conversion (4.80 and 4.06, respectively). Diets enriched with soybean grain or protected fat do not promote significant differences on carcass traits and meat quality neither.
\end{abstract}

Key Words: average daily gain, carcass traits, loin eye area, sheep, tenderness, texture

\section{Introdução}

O rebanho brasileiro de ovinos é constituído de aproximadamente 16,1 milhões de cabeças. Desse efetivo, um total de cerca de um milhão de animais (6,2\% do efetivo nacional) encontra-se na Região Centro-Oeste, o que a faz a terceira maior produtora do País (Anualpec, 2009). A ovinocultura desenvolvida no estado de Mato Grosso do Sul, que era vista como uma atividade voltada para a agricultura familiar, começa a ser observada como importante fonte de 
renda dentro da empresa rural. Ao mesmo tempo, a tradição de criar os animais em pastagens exclusivas e as condições climáticas do estado são favoráveis ao desenvolvimento das verminoses, o que causa problemas sanitários, levando à redução no desempenho e elevada mortalidade dos animais. Dessa forma, a prática da desmama precoce, com cria e terminação dos cordeiros em regime de confinamento, torna-se uma estratégia para viabilizar a exploração.

Outro fator importante é a possibilidade de abater precocemente os animais e obter carcaças de melhor qualidade, o que reflete em melhor preço pago pelo mercado consumidor e garante ao produtor retorno mais rápido do capital investido (Oliveira et al., 2002). Todavia, essa estratégia produtiva pressupõe investimentos adicionais, como instalações e, principalmente, alimentação. Dessa forma, existe a necessidade de avaliar alimentos que possam proporcionar aporte nutricional adequado aos animais e, por conseqüência, garantir melhores índices de desempenho, com reflexos positivos no rendimento da carcaça e na qualidade da carne.

Segundo Jaeger et al. (2004), gorduras e óleos têm sido utilizados na alimentação de ruminantes em substituição às altas proporções de grãos, com o intuito de aumentar a densidade energética da dieta e melhorar a eficiência alimentar. Porém, Homem Júnior et al. (2010) observaram que dietas para terminação de cordeiros Santa Inês, com elevada proporção de concentrado, contendo grãos de girassol ou gordura protegida proporcionaram bom desempenho aos animais, mas não diferiram da dieta sem adição de fontes lipídicas.

Assim, o objetivou-se neste trabalho avaliar o desempenho, as características de carcaça e a qualidade da carne de cordeiros Santa Inês, terminados em confinamento e alimentados com dietas contendo soja grão ou gordura protegida.

\section{Material e Métodos}

O experimento foi desenvolvido no módulo de confinamento do Setor de Ovinocultura do Instituto São Vicente, Campo Grande, Mato Grosso do Sul.

As instalações eram compostas de 24 baias individuais com $3 \mathrm{~m}^{2}$ cada, cobertas e com piso concretado, equipadas com bebedouros e cochos de forma a permitir o arraçoamento individual dos animais.

Foram utilizados 24 cordeiros machos não-castrados da raça Santa Inês, com peso corporal inicial de 19,30 $\pm 1,77 \mathrm{~kg}$ e média de idade de cinco meses, nascidos em uma mesma estação de parição e provenientes do próprio rebanho do Instituto São Vicente. Todos os animais foram identificados com brincos e receberam tratamento para controle e prevenção de endoparasitas $(2 \mathrm{~mL}$ de cloridrato de levamisol em dose única e $1 \mathrm{~mL}$ para cada $4 \mathrm{~kg}$ peso corporal de sulfaquinoxalina sódica em três doses com intervalos de 24 h), antes do período de adaptação ao confinamento.

Os animais foram sorteados aleatoriamente nos tratamentos e adaptados às instalações, ao manejo e ao consumo das dietas durante 21 dias. As três dietas experimentais (Tabela 1) foram formuladas para ganho diário de 200 g, seguindo as exigências nutricionais para animais com menor ímpeto de crescimento, estimadas pelo sistema NRC (2007).

Os ingredientes e os concentrados, já misturados, foram submetidos às análises bromatológicas, antes do início e periodicamente durante o confinamento, objetivando averiguar a qualidade nutricional das dietas. A formulação de cada dieta foi ajustada ao final de cada período de 28 dias, de acordo com o incremento de peso corporal, visando atender os requerimentos nutricionais dos animais e manter o nível desempenho desejado.

Tabela 1- Composição percentual (\% MS) e características nutricionais das dietas

\begin{tabular}{|c|c|c|c|}
\hline \multirow[b]{2}{*}{ Ingrediente } & \multicolumn{3}{|c|}{ Dieta } \\
\hline & Controle & Soja grão & Gordura protegida \\
\hline Feno de capim-tifton 85 & 40,0 & 40,0 & 40,0 \\
\hline Farelo de soja & 15,0 & 10,0 & 10,0 \\
\hline Ureia & 0,5 & 0,4 & 1,0 \\
\hline Soja grão & - & 7,6 & - \\
\hline Gordura protegida $^{1}$ & - & - & 4,8 \\
\hline \multicolumn{4}{|l|}{ Composicão nutricional } \\
\hline Proteína bruta (\% da MS) & 13,2 & 13,0 & 13,0 \\
\hline Extrato etéreo (\% da MS) & 2,2 & 6,0 & 6,0 \\
\hline Energia metabolizável (MJ/kg MS) & 10,4 & 11,8 & 12,2 \\
\hline Ganho estimado (g/dia) & 200 & 200 & 200 \\
\hline
\end{tabular}

${ }^{1}$ Produto comercial à base de óleo de soja complexado com cálcio (Megalac-E ${ }^{\circledR}$ - Arm \& Hammer). 
Foram oferecidas duas refeições diárias, às 7 e às 14 h, preconizou-se $10 \%$ de sobras, para caracterizar o consumo ad libtum. Os alimentos foram fornecidos na forma de ração completa, sendo o concentrado e o volumoso misturados diretamente no cocho.

As sobras foram retiradas a cada dois dias, agrupadas em períodos de 28 dias e permaneceram acondicionadas em congelador a $-20^{\circ} \mathrm{C}$. Ao final de cada período, as sobras foram encaminhadas ao laboratório para análise de matéria seca (MS), proteína bruta (PB), extrato etéreo (EE), segundo procedimentos descritos pela AOAC (1990), permitindo assim estimar a ingestão de nutrientes pelos animais e a conversão alimentar (kg de matéria seca ingerida/kg de peso ganho). As pesagens dos animais foram realizadas ao início do período experimental e a cada intervalo de 28 dias, utilizando-se balança mecânica com capacidade para $100 \mathrm{~kg}$.

Ao final do período experimental os animais foram abatidos no abatedouro experimental da Fazenda Escola, seguindo os procedimentos de insensibilização por eletronarcose e posterior sangria por seç̧ão das veias jugulares e artérias carótidas (Cezar \& Souza, 2007). No abate foram obtidos os pesos de carcaça quente, das gorduras pélvica, perirrenal e inguinal, do fígado e dos rins, além das medidas de comprimento interno das carcaças. $\mathrm{O}$ rendimento de carcaça foi obtido pela relação entre o peso de carcaça quente (PCQ) e o peso ao abate (PA) dos animais. Em seguida, as carcaças foram transportadas à câmara frigorífica por 24 horas à temperatura de $3^{\circ} \mathrm{C}$. Decorrido este tempo, as carcaças foram pesadas para a obtenção do peso de carcaça resfriada (PCR), calculando-se o rendimento de carcaça fria (RCF) pela relação entre o peso de carcaça resfriada (PCR) e o peso de abate (PA).

As carcaças foram divididas longitudinalmente: a metade esquerda foi seccionada em cortes comerciais de paleta, perna, costilhar (contendo as porções musculares da região ventral) e pescoço, e estes, posteriormente pesados para estimar o rendimento em relação ao peso da carcaça fria. Todas as subdivisões e mensurações realizadas nas carcaças seguiram as recomendações de Osório \& Osório (2005).

Em um corte transversal entre a $12^{\mathrm{a}}$ e $13^{\mathrm{a}}$ costelas, expondo o músculo Longissimus dorsi foi realizada a medida da espessura de gordura, obtida no terceiro quarto da altura desse músculo a partir da coluna vertebral, com auxílio de um paquímetro. Por meio de decalque do perímetro do músculo, em papel vegetal a área de olho de lombo foi mensurada, posteriormente, por planimetria utilizando o software AutoCAD R14, conforme descrito por Cezar \& Sousa (2007).
Foram retiradas três amostras do músculo longissimus dorsi, na altura da $12 \stackrel{\text { a }}{ }$ costela com aproximadamente $2,5 \mathrm{~cm}$ de espessura e imediatamente encaminhadas ao laboratório para as análises de cor da carne, capacidade de retenção de água, força de cisalhamento, perda de líquido durante o cozimento e sensorial por painel de degustação. As determinações da cor da carne foram realizadas conforme descrito por Houben et al. (2000), utilizando-se um colorímetro (Konica Minolta ${ }^{\circledR}$ ), avaliando-se a luminosidade ( $\mathrm{L}^{*} 0=$ preto; $100=$ branco $)$, a intensidade da cor vermelha $\left(a^{*}\right)$ e a intensidade da cor amarela (b*). Trinta minutos antes da realização das avaliações, foi realizado um corte transversal ao músculo, para exposição da mioglobina ao oxigênio, conforme descrito por Abularach et al. (1998). Após as avaliações de coloração de cada bife, foi retirada uma amostra de aproximadamente 2,0 g para determinação da capacidade de retenção de água, sendo o valor obtido por diferença entre os pesos da amostra antes e depois de submetida à pressão de $10 \mathrm{~kg}$, durante cinco minutos, conforme descrito por Hamm (1986).

Para a análise de perda de água no cozimento, as amostras de carne foram assadas em forno a gás à temperatura de $175^{\circ} \mathrm{C}$, até atingirem $75^{\circ} \mathrm{C}$ no seu centro geométrico, mensurada através de um termômetro digital de sonda, conforme descrito por Fernandes et al. (2009). Os pesos das amostras antes e depois da cocção foram utilizados para os cálculos das perdas totais. Após o resfriamento, foram retirados dois cilindros de cada amostra, com 1,3 cm de diâmetro, com o auxílio de uma sonda vazada padronizada, para determinar a força de cisalhamento em um texturômetro, aclopado à lâmina Warner Bratzler. Posteriormente foi calculada a média de força de corte dos cilindros para representar a força de cisalhamento de cada amostra.

Na análise sensorial, as amostras de carne foram salgadas com 1,5\% de sal em relação aos seus pesos e assadas em forno pré-aquecido a $175^{\circ} \mathrm{C}$, permanecendo até a temperatura interna da carne atingisse $75^{\circ} \mathrm{C}$. A degustação foi efetuada posteriormente por 10 provadores treinados, utilizando-se escala hedônica de nove pontos, considerando os atributos sabor (sensação de gosto e odor liberados pela amostra durante a mastigação), textura (percepção da força necessária para obter o cisalhamento da amostra ao morder) e aparência (visualização do produto).

Os resultados das variáveis obtidas foram submetidos à análise de variância utilizando o procedimento GLM (SAS, 2001). Foi adotado um modelo inteiramente ao acaso com três tratamentos e oito repetições. As médias foram comparadas pelo teste Tukey, considerando o nível de significância de $5 \%$ de probabilidade, quando o teste $\mathrm{F}$ foi significativo para as variáveis. Para as características 
sensoriais da carne (sabor, textura e aparência) foi utilizado o teste não paramétrico de Kruskal - Wallis, conforme descrito por Sampaio (2002).

\section{Resultados e Discussão}

Não foram encontradas diferenças significativas $(\mathrm{P}>0,05)$ nas variáveis relacionadas às ingestões de matéria seca (IMS) e proteína bruta (IPB) (Tabela 2). As dietas contendo soja grão (SG) e gordura protegida (GP) proporcionaram $(\mathrm{P}<0,05)$ maior ingestão de extrato etéreo (EE), o que reflete o nível mais elevado deste nutriente nas dietas com suplementação lipídica, uma vez que não foi observada diferença na ingestão de matéria seca.

Os efeitos negativos esperados na ingestão das dietas com elevada concentração de EE no caso das dietas com gordura protegida e soja grão não foram observados. Segundo Johnson \& McLure (1973), quantidades elevadas de lipídeos nas dietas de ruminantes podem prejudicar a ingestão matéria seca. Esse efeito negativo pode ser causado por problemas na aceitabilidade das rações e também pela redução da digestibilidade das frações fibrosas. Mas, segundo relatado por Allen (2000), fontes de gordura protegidas da fermentação ruminal, como no caso dos sais de cálcio de ácidos graxos ou grãos de oleaginosas, que apresentam proteção natural, são inertes à população microbiana e, desta forma, não exercem efeito negativo sobre o processo de degradação da fração fibrosa.

A dieta contendo gordura protegida proporcionou $(\mathrm{P}<0,05)$ maior ganho de peso diário em comparação à controle. Os animais que consumiram a dieta com soja grão apresentaram comportamento intermediário para esta variável. Os grupos soja grão e gordura protegida também apresentaram $(\mathrm{P}<0,05)$ melhores resultados de conversão alimentar (CA) e eficiência proteica (EP).

Brandt \& Anderson (1995), avaliando o uso de dietas contendo gordura na terminação de bovinos em confinamento, encontraram aumento no ganho de peso diário e melhor conversão alimentar. Da mesma forma, Zinn \& Shen (1996) também relataram melhor eficiência alimentar e concluíram que esse resultado associa-se aos maiores teores de energia metabolizável nos lipídios em relação aos carboidratos e proteína.

Neste trabalho, foram utilizados animais jovens e em pleno crescimento, fase caracterizada pela maior deposição de tecido muscular em relação ao tecido adiposo. Aparentemente, ao elevar o teor de energia metabolizável da ração, com a adição de fontes lipídicas, aumentou-se também a eficiência de utilização da proteína dietética disponível para o crescimento muscular, corroborando os resultados anteriormente descritos.

Não foram observadas diferenças $(\mathrm{P}>0,05)$ no peso de carcaça resfriada, comprimento interno da carcaça, área de olho-de-lombo, espessura de gordura subcutânea, peso de fígado e peso de rins. As dietas com soja grão e gordura protegida proporcionaram $(\mathrm{P}<0,05)$ maiores pesos ao abate (PA), pesos de carcaça quente (PCQ) e melhores rendimentos de carcaça quente (RCQ). A dieta com gordura protegida proporcionou maior deposição de gordura perirenal, pélvica e inguinal (PGPPI) (Tabela 3).

Os rendimentos de carcaça quente obtidos com as dietas com soja grão e gordura protegida foram semelhantes aos observados por Rodrigues et al. (2008), que avaliaram níveis crescentes de inclusão de polpa cítrica em dietas para terminação de cordeiros Santa Inês em confinamento. Esses autores abateram os animais com aproximadamente $33,5 \mathrm{~kg}$ e obtiveram valor médio de 49,9\% para essa variável. Garcia et al. (2000), relataram RCQ de 53,1\% em cordeiros Santa Inês terminados em confinamento e alimentados com dietas com elevada proporção de concentrado. Nesse trabalho, os animais foram abatidos com peso médio de $36,7 \mathrm{~kg}$. Neres et al. (2001) trabalharam com animais $3 / 4$ Suffolk terminados em pastagem de grama-estrela-branca recebendo suplementação com concentrado. Os animais foram abatidos com peso médio de 25,1 kg e apresentaram rendimento de carcaça de aproximadamente 53\%. Desta forma, é possível

Tabela 2 - Ingestão de nutrientes e desempenho de cordeiros Santa Inês terminados em confinamento e alimentados com dietas contendo soja grão ou gordura protegida

\begin{tabular}{|c|c|c|c|c|c|}
\hline \multirow[b]{2}{*}{ Variável } & \multicolumn{3}{|c|}{ Dieta } & \multirow[b]{2}{*}{$\mathrm{CV} \%$} & \multirow[b]{2}{*}{ Probabilidade } \\
\hline & Controle & Soja em grão & Gordura protegida & & \\
\hline Ingestão de matéria seca (kg/dia) & 1,05 & 0,94 & 1,02 & 18,80 & 0,66 \\
\hline Ingestão de proteína bruta (kg/dia) & 0,13 & 0,12 & 0,13 & 16,66 & 0,63 \\
\hline Ingestão de extrato etéreo (kg/dia) & $0,023 b$ & $0,056 \mathrm{a}$ & $0,061 \mathrm{a}$ & 18,44 & 0,04 \\
\hline Ganho de peso diário (kg/dia) & $0,16 b$ & $0,19 \mathrm{ab}$ & $0,24 \mathrm{a}$ & 18,42 & 0,02 \\
\hline Conversão alimentar (kg MS/ kg de peso ganho) & $6,40 \mathrm{a}$ & $4,80 \mathrm{~b}$ & $4,06 b$ & 14,93 & 0,02 \\
\hline Eficiência proteica (kg de peso ganho/kg de PB) & $1,22 \mathrm{c}$ & $1,62 b$ & $1,94 \mathrm{a}$ & 14,74 & 0,03 \\
\hline
\end{tabular}

Médias seguidas de letras diferentes diferem pelo teste Tukey a 5\% de probabilidade.

$\mathrm{P}=$ probabilidade. 
verificar que ao se utilizar raças especializadas para produção de carne, com carcaças de melhor conformação, o abate mais precoce é possível e não prejudica o rendimento.

Cunha et al. (2008) não observaram influência dos níveis de caroço de algodão e consequente quantidade de extrato etéreo na dieta $(\mathrm{P}>0,05)$ sobre as características peso corporal vazio, peso de carcaça quente, peso de carcaça fria, rendimento de carcaça quente e rendimento de carcaça fria, cujas médias foram de 27,17; 15,35; 15,02 kg; 47,64 e 46,60\%, respectivamente.

A medida da AOL realizada no músculo longissimus tem indicado relação direta com o total de músculos da carcaça, enquanto a espessura de gordura subcutânea, com o total de gordura na carcaça e indiretamente com a quantidade de músculos, uma vez que, quanto maior o acúmulo de gordura, menor a proporção de músculos (Lawrie, 2005). Cunha et al. (2008) observaram efeito linear decrescente $(\mathrm{P}<0,01)$ para a AOL; com decréscimo de $0,063 \mathrm{~cm}^{2}$ para cada unidade de aumento no nível de caroço de algodão na dieta.

Com base nessas informações pode-se afirmar que os cordeiros Santa Inês apresentam potencial para produção de carcaças com bom rendimento, desde que os animais recebam aporte nutricional adequado e sejam abatidos com peso corporal aproximado $35 \mathrm{~kg}$. Ressalta-se que a decisão de manter os animais até o peso sugerido, encontra-se diretamente condicionada ao custo de produção e oportunidade de venda desses animais.

As dietas avaliadas não tiveram $(\mathrm{P}>0,05)$ efeitos significativos para os pesos e os rendimentos principais cortes comerciais dos cordeiros Santa Inês terminados em confinamento (Tabela 4).

Em trabalho desenvolvido por Cartaxo et al. (2009), foram avaliados os efeitos dos grupos genéticos e da condição corporal ao abate sobre as características de carcaça de cordeiros Santa Inês e mestiços Dorper $\times$ Santa Inês terminados em confinamento. Os autores verificaram que os animais abatidos na condição gorda (escores 4,0 a 5,0 obtidos por avaliação visual e palpação lombar), independentemente do grupo genético, não apresentaram diferenças com relação ao peso e rendimento dos principais cortes comerciais. Entretanto, os resultados obtidos foram inferiores ao deste trabalho, com médias de 2,37 e 1,36 kg e 30,93 e $17,83 \%$ para o peso e rendimento de perna e paleta, respectivamente.

Tabela 3 - Características de carcaça de cordeiros Santa Inês terminados em confinamento e alimentados com dietas contendo soja grão ou gordura protegida

\begin{tabular}{|c|c|c|c|c|c|}
\hline \multirow[b]{2}{*}{ Variável } & \multicolumn{3}{|c|}{ Dieta } & \multirow[b]{2}{*}{$\mathrm{CV} \%$} & \multirow[b]{2}{*}{ Probabilidade } \\
\hline & Controle & Soja em grão & Gordura protegida & & \\
\hline Peso ao abate (kg) & $34,20 b$ & $35,90 a$ & $37,50 a$ & 15,34 & 0,03 \\
\hline Peso de carcaça quente (kg) & $16,20 \mathrm{~b}$ & $17,70 \mathrm{a}$ & $18,75 \mathrm{a}$ & 18,67 & 0,04 \\
\hline Rendimento de carcaça quente (\%) & $47,40 \mathrm{~b}$ & $49,40 \mathrm{a}$ & $50,05 a$ & 4,49 & 0,04 \\
\hline Peso de carcaça resfriada (kg) & 16,70 & 16,90 & 17,50 & 18,85 & 0,92 \\
\hline Comprimento interno da carcaça (cm) & 60,00 & 61,40 & 63,00 & 14,64 & 0,32 \\
\hline Área de olho-de-lombo $\left(\mathrm{cm}^{2}\right)$ & 11,19 & 12,43 & 12,95 & 25,21 & 0,58 \\
\hline Espessura de gordura subcutânea (mm) & 1,48 & 1,56 & 1,80 & 22,75 & 0,79 \\
\hline Peso de fígado (kg) & 0,51 & 0,48 & 0,49 & 14,39 & 0,81 \\
\hline Peso dos rins (kg) & 0,09 & 0,09 & 0,08 & 9,35 & 0,88 \\
\hline Peso da gordura perirrenal (kg) & $0,16 \mathrm{~b}$ & $0,22 \mathrm{ab}$ & $0,28 a$ & 23,69 & 0,04 \\
\hline
\end{tabular}

Médias seguidas de letras diferentes diferem pelo teste de Tukey a 5\% de probabilidade.

CV\% - coeficiente de variação.

Tabela 4 - Peso e rendimento dos principais cortes comerciais de cordeiros Santa Inês terminados em confinamento com dietas contendo soja grão ou gordura protegida

\begin{tabular}{|c|c|c|c|c|c|}
\hline \multirow[b]{2}{*}{ Variável } & \multicolumn{3}{|c|}{ Dieta } & \multirow[b]{2}{*}{$\mathrm{CV} \%$} & \multirow[b]{2}{*}{ Probabilidade } \\
\hline & Controle & Soja grão & Gordura protegida & & \\
\hline Peso de paleta (kg) & 1,45 & 1,49 & 1,54 & 17,16 & 0,82 \\
\hline Peso de perna (kg) & 2,52 & 2,55 & 2,55 & 18,12 & 0,98 \\
\hline Peso de costilhar (kg) & 3,15 & 3,19 & 3,40 & 21,91 & 0,46 \\
\hline Peso de pescoço (kg) & 1,66 & 1,74 & 1,97 & 6,86 & 0,87 \\
\hline Rendimento de paleta (\%) & 17,36 & 17,76 & 17,67 & 9,96 & 0,85 \\
\hline Rendimento de perna (\%) & 30,43 & 29,96 & 29,31 & 7,24 & 0,67 \\
\hline Rendimento de costilhar (\%) & 37,80 & 37,21 & 38,87 & 9,65 & 0,19 \\
\hline Rendimento de pescoço (\%) & 9,88 & 10,09 & 11,12 & 3,12 & 0,54 \\
\hline
\end{tabular}

Médias seguidas de letras diferentes diferem pelo teste de Tukey a 5\% de probabilidade.

CV\% = coeficiente de variação.

$\mathrm{P}=$ probabilidade . 
O peso e o rendimento dos principais cortes comerciais não foram influenciados pelos tratamentos experimentais ( $P>0,05)$. Segundo Osório et al. (2002), quando os animais apresentam uma mesma conformação corporal, como no caso de uma mesma raça e também semelhança no peso de carcaça e composição tecidual de músculo e gordura, conforme visualizado pelos valores semelhantes de AOL e EGC neste estudo (Tabela 3), a composição regional das carcaças são similares.

As diferentes dietas não tiveram efeitos significativos $(\mathrm{P}>0,05)$ nas características quantitativas da qualidade da carne (Tabela 5).

Os resultados das perdas no cozimento (PCOZ) observados foram semelhantes aos obtidos por Rodrigues et al. (2008), ao avaliaremm a carne de cordeiros Santa Inês, terminados em confinamento. Esses autores observaram valores de PCOZ de cerca de $20 \%$ e relataram que esta variável pode estar associada à quantidade de gordura na carcaça. Essa observação pode ser confirmada pelos dados apresentados por Sañudo (2008), que demonstrou diminuição nas perdas por cozimento com o aumento da quantidade de gordura na carcaça.

A força de cisalhamento média apresentada pelas amostras do lombo dos animais, de aproximadamente $2,2 \mathrm{~kg}$, indicou que a carne dos cordeiros do presente trabalho pode ser considerada macia, segundo valores apresentados por Cezar \& Souza (2007). Segundo Osório et al. (1998) é possível verificar que, depois que o animal completa aproximadamente 5 meses de idade, a carne ovina apresenta tendência de diminuição desta característica.

A capacidade de retenção de água (CRA) é uma característica qualitativa de grande importância, pois afeta a aparência, o comportamento da carne durante o cozimento e também a suculência durante a mastigação. Neste estudo, o valor médio variou de 59,84 a 61,06 e foi semelhante ao observado por Rodrigues etal. (2008), de60,1. Aparentemente, os principais fatores determinantes da CRA são a velocidade de queda e o pH final observado após os processos bioquímicos de conversão de músculo em carne. Segundo Lawrie (2005), a água é mantida por capilaridade, associada aos filamentos proteicos. Desta forma, a glicólise post-morten normal deve ocorrer até um $\mathrm{pH}$ final em torno de 5,5, ponto isoelétrico das principais proteínas do músculo, responsáveis pela capacidade de retenção de água.

O valor médio de $\mathrm{pH}$, de aproximadamente 5,68, observado neste estudo pode ser considerado normal para a carne ovina, como relatado por Silva Sobrinho et al. (2005), que trabalharam com animais de diferentes grupos genéticos e observaram valor médio de 5,6. Segundo Cezar \& Souza (2007), valores finais de $\mathrm{pH}$ inferiores a 5,4 favorecem a ocorrência de carne PSE (pale, soft, exudative), que, em ovinos, em particular, raramente é observada. A condição PSE proporciona menor capacidade de retenção de água, tornando também a carne flácida e pálida e comprometendo a aceitação pelo consumidor. Em contrapartida, valores acima de 6,0, provoca o escurecimento (DFD - dark, firm, dry), maior capacidade de retenção de água e maior atividade enzimática na carne, diminuindo sua vida de prateleira (Lawrie, 2005).

Não foram observadas diferenças $(\mathrm{P}>0,05)$ nos principais atributos de qualidade relativos às características sensoriais da carne (Tabela 6).

De modo geral e pelas notas atribuídas pelo painel sensorial, a carne dos cordeiros apresentou boa aceitação e características que agradaram ao consumidor. Essa observação pode ser confirmada pela análise combinatória dos resultados das avaliações quantitativas, que não demonstraram nenhum problema qualitativo nas amostras avaliadas, com as notas atribuídas pelos painelistas.

Segundo Lawrie (2005), a força de cisalhamento é o método de avaliação quantitativa que pode apresentar maior distorção quando correlacionada às notas obtidas para essa variável no painel de degustação. A base do método mecânico de avaliação é a força de corte, ou seja, uma medida objetiva. A impressão da textura na avaliação sensorial envolve a facilidade da penetração dos dentes na

Tabela 5 - Características quantitativas da qualidade da carne de cordeiros Santa Inês terminados em confinamento recebendo dietas contendo soja grão ou gordura protegida

\begin{tabular}{|c|c|c|c|c|c|}
\hline \multirow[b]{2}{*}{ Variável } & \multicolumn{3}{|c|}{ Dieta } & \multirow[b]{2}{*}{$\mathrm{CV} \%$} & \multirow[b]{2}{*}{ Probabilidade } \\
\hline & Controle & Soja grão & Gordura protegida & & \\
\hline Perdas no cozimento (\%) & 20,64 & 20,84 & 20,12 & 7,05 & 0,76 \\
\hline Força de cisalhamento (kg) & 2,28 & 2,14 & 2,11 & 5,44 & 0,16 \\
\hline Capacidade de retenção de água (\%) & 59,84 & 61,06 & 61,00 & 3,12 & 0,53 \\
\hline $\mathrm{pH}$ & 5,67 & 5,75 & 5,62 & 1,17 & 0,16 \\
\hline Luminosidade (L*) & 40,00 & 41,00 & 41,50 & 3,69 & 0,34 \\
\hline Intensidade de vermelho $\left(\mathrm{a}^{*}\right)$ & 14,84 & 14,88 & 15,05 & 2,65 & 0,71 \\
\hline Intensidade de amarelo (b*) & 7,02 & 7,04 & 7,15 & 3,04 & 0,64 \\
\hline
\end{tabular}

Intensidade de amarelo (b*)

CV\% = coeficiente de variação

$\mathrm{P}=$ probabilidade. 
Tabela 6 - Características sensoriais da carne de cordeiros Santa Inês terminados em confinamento recebendo dietas contendo soja grão ou gordura protegida

\begin{tabular}{|c|c|c|c|c|c|}
\hline \multirow[b]{2}{*}{ Variável } & \multicolumn{3}{|c|}{ Dieta } & \multirow[b]{2}{*}{ CV\% } & \multirow[b]{2}{*}{ Probabilidade } \\
\hline & Controle & Soja grão & Gordura protegida & & \\
\hline Sabor & 7,07 & 7,33 & 7,40 & 17,92 & 0,33 \\
\hline Aparência & 7,12 & 7,31 & 7,16 & 17,88 & 0,58 \\
\hline
\end{tabular}

${ }^{1}$ Notas atribuídas por painel de degustação; 9 - aprovação máxima; 1 - desaprovação máxima

$\mathrm{CV} \%$ = coeficiente de variação.

carne e da sua desintegração na boca e a quantidade de resíduo após a mastigação, o que torna essa análise muito mais complexa e, muitas vezes, dificulta a correlação entre métodos de estudo.

\section{Conclusões}

A soja grão e a gordura protegida, ao ser utilizadas em dietas para terminação de cordeiros Santa Inês, proporcionam melhor desempenho dos animais e carcaças mais pesadas sem interferir na qualidade da carne.

\section{Agradecimentos}

À Universidade Católica Dom Bosco pelo apoio durante o desenvolvimento deste trabalho.

\section{Referências}

ABULARACH, M.L.; ROCHA, C.E.; FELÍCIO, P.E. Características de qualidade do contra-filé (m. L. dorsi) de touros jovens da raça Nelore. Ciência e Tecnologia de Alimentos, v.18, n.2, p.205-210, 1998.

ALLEN, M.S. Effects of diet on short-term regulation of feed intake by lactating dairy cattle. Journal of Animal Science, v.83, n.7, p.1598-1630, 2000.

ANUALPEC. Anuário da pecuária brasileira. AGRA FNP, n.1, v.14, p.368, 2007.

ASSOCIATION OF OFFICIAL ANALYTICAL CHEMISTS - AOAC. Official methods of analysis. 15.ed. Washington, 1990. 1422p.

BRANDT JUNIOR, R.T.; ANDERSON, S.J. Use of supplemental fat to optimize net energy intake by feedlot cattle. In: Proceedings Intake by Feedlot Cattle. 942p. Stillwater: Oklahoma State University, 1995. p.303-311.

CARTAXO, F.Q.; CEZAR, M.F.; SOUZA, W.H. et al. Características quantitativas da carcaça de cordeiros terminados em confinamento e abatidos em diferentes condições corporais. Revista Brasileira de Zootecnia, v.38, n.4, p.697-704, 2009.

CEZAR, M.F.; SOUZA, W.H. Carcaças ovinas e caprinas obtenção, avaliação e classificação. Uberaba: Editora Agropecuária Tropical, 2007. 232p.

CUNHA, M.G.G.; CARVALHO, F.F.R.; GONZAGA NETO, S. et al. Características quantitativas de carcaça de ovinos Santa Inês confinados alimentados com rações contendo diferentes níveis de caroço de algodão Integral. Revista Brasileira de Zootecnia, v.37, n.6, p.1112-1120, 2008.

FERNANDES, A.R.M.; SAMPAIO, A.A.M.; HENRIQUE, W. et al. Composição em ácidos graxos e qualidade da carne de tourinhos
Nelore e Canchim, terminados em confinamento e alimentados com dietas à base de cana-de-açúcar e dois níveis de concentrado. Revista Brasileira de Zootecnia, v.38, n.2, p.328-337, 2009. GARCIA, I.F.F.; PEREZ, J.R.O.; OLIVEIRA, M.V. Características de carcaça de cordeiros Texel x Bergamácia, Texel x Santa Inês e Santa Inês puros, terminados em confinamento, com casca de café como parte da dieta. Revista Brasileira de Zootecnia, v.29, n.1, p.253-260, 2000.

HAMM, R. Functional properties of the miofibrilar system and their measurement. In: BECHTEL, P.J. (Ed.) Muscle as food. Orlando: Academic Press, 1986. p.135-199.

HOMEM JÚNIOR, A.C.; EZEQUIEL, J.M.B.; GALATI, R.L. et al. Grãos de girassol ou gordura protegida em dietas com alto concentrado e ganho compensatório de cordeiros em confinamento. Revista Brasileira de Zootecnia, v.39, n.3, p.563-571, 2010

HOUBEN, J.H.; VAN DIJK, A.; EIKELENBOOM, G. et al. Effect of dietary vitamin E supplementation, fat level and packaging on color stability and lipid oxidation in minced meat. Meat Science, v.55, n.3, p.331-336, 2000.

JAEGER, S.M.P; DUTRA, A.R.; PEREIRA, J.C. et al. Características da carcaça de bovinos de quatro grupos genéticos submetidos a dietas com ou sem adição de gordura protegida. Revista Brasileira de Zootecnia, v.33, n.6, p.1876-1887, 2004 (supl.1).

JOHNSON, R.R.; McLURE, K.E. High fat rations for ruminants. II. Effects of fat added to corn plant material prior to ensiling on digestibility and voluntary intake of the silage. Journal of Animal Science, v.36, p.397, 1973.

LAWRIE, R.A. Ciência da carne. 6.ed. Porto Alegre: Artmed, 2004. 384p.

NATIONAL RESEARCH COUNCIL - NRC. Nutrient requerements of sheep. Washington: National Academy Press, 2007. 408p.

NERES, M.A.; MONTEIRO, A.L.G.; GARCIA, C.A. et al. Forma física da ração e pesos de bate nas características de carcaça de cordeiros em creep feeding. Revista Brasileira de Zootecnia, v.30, n.3, 948-954, 2001.

OLIVEIRA, M.V.M.; PÉREZ, J.R.O.; ALVES, E.L. et al. Avaliação da composição de cortes comerciais, componentes corporais e órgãos internos de cordeiros confinados e alimentados com dejetos de suínos. Revista Brasileira de Zootecnia, n.3, v.31, p.1459-1468, 2002 (supl.).

OSÓRIO, J.C.S.; OLIVEIRA, N.M.; OSÓRIO, M.T.M. et al. Produção de carne em cordeiros cruza Border Leicester com ovelhas Corriedale e Ideal. Revista Brasileira de Zootecnia, v.31, n.3, p.1469-1480, 2002.

OSÓRIO, J.C.; OSÓRIO, M.T.; JARDIM, P. et al. Métodos para avaliação de carne ovina: "in vivo", na carcaça e na carne. Pelotas: Universidade Federal de Pelotas, 1998a. 107p.

OSÓRIO, J.C.S.; OSÓRIO, M.T.M. Produção de carne ovina. Técnicas de avaliação in vivo e na carcaça. 2.ed. Pelotas: Editora Universitária, 2005, 82p.

RODRIGUES, G.H.; SUSIN, I.; PIRES, A.V. et al. Polpa cítrica em rações para cordeiros em confinamento: características de carcaça e qualidade da carne. Revista Brasileira de Zootecnia, v.37, n.10, p.1869-1875, 2008. 
SAMPAIO, I.B.M. Estatística aplicada à experimentação animal. 2.ed. Belo Horizonte: FEPMVZ, 2002. 265p.

SAÑUDO, C. Qualidade da carne ovina e caprina em face ao desenvolvimento da percepção do consumidor. Revista Brasileira de Zootecnia, v.37, p.143-160, 2008 (supl. especial).

SILVA SOBRINHO, A.G.; PURCHAS, R.W.; KADIM, I.T. et al. Características de qualidade da carne de ovinos de diferentes genótipos e idades ao abate. Revista Brasileira de Zootecnia, v.34, n.3, p.1070-1078, 2005.

STATISTICAL ANALYSIS SYSTEM - SAS. User's guide. Cary: Statistics, 2001. (CD-ROM).

ZINN, R.A.; SHEN, Y. Interaction of dietary calcium and supplemental fat on digestive function and growth performance in feedlot steers. Journal of Animal Science, v.74, n.8, p.2303-2309, 1996. 